\title{
Maternal and Newborn Risk Factors associated With Neonatal Mortality in Gitwe District Hospital in Ruhango District, Rwanda
}

\author{
Théoneste NDAYISENGA ${ }^{1 *}$
}

\section{Théoneste NDAYISENGA}

Institut Supérieur Pédagogique De Gitwe, Faculty Of Medical Laboratory Technology, Southern Province, RWANDA

\section{Correspondence}

Théoneste NDAYISENGA,

P.O BOX 01 Nyanza

Phone no: +250 788633491

Email: ndathe1976@yahoo.fr (or) ndayisenga54@gmail.com

\section{History}

- Submission Date: 31-12-15;

- Review completed: 16-02-16;

- Accepted Date: 20-03-16.

DOI : 10.5530/ijmedph.2016.2.9

Article Available online

http://www.ijmedph.org/v6/i2

\section{Copyright}

(C) 2016 Phcog.Net. This is an open-access article distributed under the terms of the Creative Commons Attribution 4.0 International license.

\begin{abstract}
Background: The risk factors of neonatal mortality are complex, this health indicator is relatively improved slowly and its decreasing trend is not as great as other health indicators such as infant and under 5 years children mortality rates. This study aimed at identifying the risk factors of neonatal mortality in Gitwe District Hospital, based on observational casecontrol study design.
\end{abstract}

Methods: A total of 3782 neonates, who took post-neonatal care at Gitwe Hospital (Rwanda), were enrolled from January 2013 to July 2014; and we found 62 died neonates. By using systematic random sampling, 186 controls were selected among survivors. Maternal and neonatal data were collected and the outcome of interest was neonatal mortality. Multiple logistic regression models were used to examine the association between studied factors and neonatal mortality.

Results: The factors that highly associated with neonatal mortality $(5<\mathrm{aOR}<25, P \leq 0.001)$ were grandmultigravida, HIV+, incomplete antenatal care visits, eclampsia, delivering at home, prolonged labor duration, and lower $1^{\text {st }}$ minute Apgar score. Other factors were less associated with neonatal mortality $(1<$ a OR $<5, P \leq 0.05)$, those are lack of health insurance, early childbearing ( $<20$ years), preterm birth, and asphyxia. Lower birth weight and lower birth spacing (aOR $<1, P \leq 0.01$ ) showed the negative association with neonatal mortality.

Conclusion: This study has identified some maternal and neonatal factors which should be used to educate health care services providers, administrators and as the whole the community so as to reduce neonatal death rates.

Key words: Case control study, District Hospital, Neonatal mortality, Risk factors, Rwanda.

\section{INTRODUCTION}

World Health Organization (WHO) defines neonatal mortality as death from the birth till $28^{\text {th }}$ day of life. ${ }^{1}$ Neonatal mortality is taken as one of the most important determinants of children health status. The causes of neonatal mortality are complex and improvement of this health indicator is relatively gradual. According to WHO estimations, 130 million infants are born each year worldwide, 4 million die in the first 28 days of life. ${ }^{1}$ Three-quarters of neonatal deaths occur in the first week, and more than one-quarter occur in the first 24 hours. ${ }^{2,3}$ More than one million babies in Africa die in the first week of their life, half of them at the first day of life. It was reported $^{2}$ that the most unseen and uncounted deaths occur at home. Neonatal deaths account for $40 \%$ of deaths under the age of 5 years worldwide.

The proportion of child deaths that occur in the neonatal period is increasing and the UN Millennium Development Goal for child survival cannot be met without substantial reductions in neonatal mortality. The neonatal mortality which occurs during the first four weeks after birth is subdivided into early neonatal death which occurs in the first week of life and late neonatal death which occurs during the period between 7 and 28 days of life. Estimations from the WHO showed ${ }^{4}$ that although underfive mortality has fallen globally from 12.2 million deaths in 1990 to 7.6 million deaths in 2010, the fall in neonatal mortality is considerably less than that in the post-neonatal period. .,6 $^{5}$

Consequently, the proportion of deaths in the neonatal period rose from $38 \%$ (4 million) of total deaths in 2000 to about $41 \%$ (3.3 million) in 2009. This may be attributable to the high emphasis on child survival programs such as nutrition, vaccination and health promotion interventions relative to hospital-related investments necessary for neonatal mortality reduction particularly in rural areas. ${ }^{8}$

By the end of 1994, the neonatal mortality rate (NMR) in Rwanda was 60 per 1000 live births. Towards the end of 2010, NMR was reduced to 27 per 1000 live births. ${ }^{9}$ As NMR decreased not at the same speed as other health indicators, there are few studies conducted to know determinants of
Cite this article : Théoneste NDAYISENGA. Maternal and Newborn Risk Factors associated With Neonatal Mortality in Gitwe District Hospital in Ruhango District, Rwanda. Int. J. Med. Public Health, 2016; 6(2):98-102. 
neonatal deaths in Rwanda's district hospitals. Therefore, this study has the purpose of determining maternal and newborn risk factors associated with neonatal mortality in Gitwe District Hospital. The hospital is located in Ruhango district, the southern province of Rwanda.

\section{MATERIALS AND METHODS}

The data were extracted from mothers and neonates files stored in maternity and neonatology units of Gitwe District Hospital, with the aim of exploring maternal and newborn risk factors associated with neonatal mortality. As part of this survey, a case-control study was carried out. Neonatal deaths (less than 28 days of age) as cases, and survivors of the neonatal period as controls, were considered as they were obtained through systematic random sampling. All births in the period of 1 January 2013 to 31 July $2014(\mathrm{~N}=3782)$ constituted a cohort of live births from mothers living in the Southern province, Ruhango district. All neonatal deaths which occurred in the reference period in the study area have been considered and included, unlike the controls represented the profile of survivors to the neonatal period. Births which occurred outside Gitwe District Hospital but took postnatal care service in hospital were also included. Stillbirths and multiple live born babies were excluded.

The total number of 3782 neonates were observed, among them 62 deaths occurred in the period of 19 months. The systematic random sampling was used to select 3 controls for each case among 3720 survivors.
This method resulted in a total sample size of 248 containing 62 cases and 186 controls.

The outcome was neonatal mortality set as a binary variable of any death from birth till the end of $28^{\text {th }}$ day of life. The independent variables were maternal factors, including socio-demographic and labor/delivery characteristics, and newborn factors including clinical characteristics. The data were analyzed using univariate and multivariate logistic regression models, reporting crude and adjusted Odds Ratio (OR) with their $95 \% \mathrm{CI}$ in each analysis.

\section{RESULTS}

A univariate logistic regression for each variable was performed separately and any risk factors that showed marked association $(P<0.05)$ with the outcome were selected for the next step of analysis.

Socio-demographic factors of mother that showed significant association with neonatal mortality in univariate logistic regression model included the unmarried mothers (Crude Odds Ratio $(\mathrm{cOR})=2.46,95 \%$ $\mathrm{CI}=1.2-5.4)$, non insured mothers $(\mathrm{cOR}=4.2,95 \% \mathrm{CI}: 1.8-10.0)$, maternal age (<20years) (cOR $=5.0,95 \% \mathrm{CI}: 2.0-12.4)$, incomplete ANC visits ( $\mathrm{cOR}=7.0,95 \% \mathrm{CI}: 3.5-13.9)$, grandmultigravida $(\mathrm{OR}=3.0$, 95\% CI:1.3-7.3), primigravida ( $\mathrm{COR}=2.3,95 \% \mathrm{CI}: 1.2-4.3)$, primipara $(\mathrm{cOR}=2.3,95 \% \mathrm{CI}: 1.2-4.4)$, and HIV $+(\mathrm{cOR}=8.6,95 \% \mathrm{CI}: 1.6-45.8)$ (Table 1).

Table 1: Socio-Demographic factors of Mothers and their association with Neonatal Mortality: Gitwe District Hospital (January, 2013 - July, 2014)

\begin{tabular}{|c|c|c|c|c|}
\hline & Cases n (\%) & Controls n (\%) & Crude OR $(95 \% \mathrm{Cl})$ & Adjusted OR $(95 \% \mathrm{Cl})$ \\
\hline \multicolumn{5}{|l|}{ Marital status } \\
\hline Married & $46(74.2)$ & $175(94.1)$ & 1 & 1 \\
\hline Unmarried & $16(25.8)$ & $23(12.4)$ & $2.46(1.2-5.4)^{*}$ & $1.89(0.6-5.8)$ \\
\hline \multicolumn{5}{|l|}{ Education attainment } \\
\hline Secondary or higher & $1(1.61)$ & $4(2.15)$ & 1 & - \\
\hline Primary & $52(83.8)$ & $162(87.1)$ & $1.4(0.6-3.2)$ & \\
\hline None & $9(14.52)$ & $20(10.75)$ & $2.0(0.8-4.5)$ & \\
\hline \multicolumn{5}{|l|}{ Occupation } \\
\hline Farmer & $57(91.94)$ & 171(91.93) & 1 & - \\
\hline Other & $5(8.06)$ & $15(8.06)$ & $1.29(0.4-4.5)$ & \\
\hline \multicolumn{5}{|l|}{ Health insurance } \\
\hline Yes & $49(79.0)$ & $175(94.1)$ & 1 & 1 \\
\hline No & $13(20.97)$ & 1195.9) & $4.2(1.8-10.0)^{\star * \star}$ & $4.1(1.4-12.5)^{\star *}$ \\
\hline \multicolumn{5}{|l|}{ Age (years) } \\
\hline$<20$ & $37(59.7)$ & 144(77.4) & $5.0(2.0-12.4)^{* * *}$ & $3.2(2.0-10.2)^{\star}$ \\
\hline $20-34$ & $13(20.9)$ & $10(5.38)$ & 1 & 1.0 \\
\hline $35+$ & $12(19.35)$ & $32(17.20)$ & $1.5(0.7-3.1)$ & \\
\hline \multicolumn{5}{|l|}{ ANC visits } \\
\hline Complete & $15(24.2)$ & $121(65.0)$ & 1 & 1 \\
\hline Incomplete & $41(66.1)$ & $47(25.2)$ & $7.0(3.5-13.9)^{* * *}$ & $6.9(3.2-15.7)^{* * *}$ \\
\hline \multicolumn{5}{|l|}{ Parity } \\
\hline Primipara(I) & $32(51.61)$ & $67(36.02)$ & $2.3(1.2-4.4)^{\star *}$ & $3(0.7-12.8)$ \\
\hline Multipara(II-IV) & $21(33.87)$ & $103(55.38)$ & 1 & 1 \\
\hline Grandmultipara $(\mathrm{V}+)$ & $9(14.52)$ & $16(8.60)$ & $2.75(0.6-7.0)$ & \\
\hline \multicolumn{5}{|l|}{ Gravidity } \\
\hline Primigravida(I) & $27(43.55)$ & $56(30.11)$ & $2.3(1.2-4.3)^{\star}$ & $1.1(0.3-4.4)$ \\
\hline Multigravida(II-IV) & $24(38.71)$ & $113(60.75)$ & 1 & 1 \\
\hline Grandmultigravida $(\mathrm{V}+)$ & $11(17.74)$ & $17(9.14)$ & $3.0(1.3-7.3)^{*}$ & $22.8(1.4-36.1)^{\star}$ \\
\hline \multicolumn{5}{|l|}{ Preexisting conditions } \\
\hline None & $51(82.26)$ & $176(94.62)$ & 1 & 1 \\
\hline HIV+ & $5(8.06)$ & $2(1.08)$ & $8.6(1.6-45.8)^{*}$ & $16.5(2.5-27.4)^{\star *}$ \\
\hline
\end{tabular}


In the final model, we found that the non insured mothers: Adjusted Odds Ratio $(\mathrm{aOR}=4.1,95 \% \mathrm{CI}: 1.4-12.5)$, early childbearing $(<20$ years) $(\mathrm{aOR}=3.2,95 \% \mathrm{CI}: 2.0-10.2)$, incomplete $\mathrm{ANC}$ visits $(\mathrm{aOR}=6.9$, 95\% CI: $3.2-15.7$ ), gravidity (grandmultigravida) (aOR $=22.8,95 \% \mathrm{CI}$ : $1.4-36.1), \mathrm{HIV}+(\mathrm{aOR}=16.5,95 \% \mathrm{CI}: 2.5-27.4)$, were associated with neonatal mortality in Gitwe District Hospital (Table 1).

Labor and delivery factors that showed significant association with neonatal mortality in univariate regression analysis included place of delivery $(\mathrm{cOR}=9.8,95 \% \mathrm{CI}: 3.0-32.12)$, non assisted labor $(\mathrm{cOR}=4.60$, $95 \% \mathrm{CI}=1.4-15.1)$, C-section $(\mathrm{cOR}=0.45,95 \% \mathrm{CI}: 0.23-0.9)$, prolonged labor duration ( $\mathrm{cOR}=11.995 \% \mathrm{CI}$ : $2.4-59.8)$, and eclampsia $(\mathrm{cOR}=12.7,95 \%$ CI: $1.4-16.4)($ Table 2$)$.

In the final model, place of delivery $(\mathrm{aOR}=8.24,95 \% \mathrm{CI}: 2.0-35)$, prolonged labor duration ( $\mathrm{aOR}=17.4,95 \% \mathrm{CI}: 2-144.2)$, and eclampsia $(\mathrm{aOR}=23,95 \% \mathrm{CI}: 2.4-25.2)$ were associated with neonatal mortality (Table 2)

Clinical characteristics of neonate at birth that showed statistical significant association with neonatal mortality included LBW $(\mathrm{cOR}=0.21$, 95\% CI: $0.1-0.4)$, very lower Apgar score ( $\mathrm{cOR}=12.5$, 95\% CI: 4.2 - 37.7), preterm birth ( $\mathrm{COR}=4.8,95 \% \mathrm{CI}: 2.5$ - 9.2), first birth rank $(\mathrm{COR}=2.1,95 \% \mathrm{CI}: 1.1-3.9)$, neonate presented feet at birth $(\mathrm{cOR}=$ 2.1, 95\% CI:1.1 - 3.9), birth spacing (with previous birth) less than 24 months $(\mathrm{cOR}=0.12,95 \% \mathrm{CI}: 0.05-0.3)$, and birth asphyxia $(\mathrm{cOR}=3.6$, 95\% CI: 2.0 - 7.0) (Table 3).

\section{DISCUSSION}

This research on "Maternal and Newborn Risk Factors Associated with Neonatal Mortality in Gitwe District Hospital in Ruhango District, Rwanda" aimed broadly at examining the maternal and newborn risk factors associated with neonatal mortality.

This study found 62 neonatal deaths among 3782 live births registered during the period of 19 months. These are equivalent to NMR of 16.4 per 1000 live births, $95 \%$ CI: $13.1-18.9$ that is smaller than that of the entire southern province (25 per 1000 live births: 95\% CI [18.7-33.4 $]^{10}$ and national statistics (20 per 1000 live births: 95\% CI [23.6-31.0] in 2014-2015. ${ }^{11}$ There are several explanations for this difference.
Initially, it may be due to an improvement of mother-to-child health in recent years: the improvement in coverage of maternal and delivery care services has highly increased, the improvement in intervention-related indicators associated with neonatal mortality delivery by health professionals, delivery in a health facility, use of ANC services, early initiation of breastfeeding, and ownership of mosquito nets for malaria prevention. ${ }^{10}$ A study in Ghana, ${ }^{12}$ for example, found that early initiation of breastfeeding may prevent $22 \%$ of all neonatal deaths.

The findings regarding the association between maternal sociodemographic factors and neonatal mortality are worth noting. Surprisingly, short preceding birth intervals and LBW, one of newborn factors, are associated with decreased risk of neonatal death. However, initiatives should continue to emphasize optimal birth spacing (two to three years) to improve neonatal health outcomes. It was reported in earlier studies ${ }^{13,14,15}$ that shorter intervals between births, high birth rank, and LBW have been reported to be strongly associated with adverse neonatal outcome including neonatal death. In contrast to the study findings, the birth rank was not shown to be associated with neonatal mortality while a shorter birth interval was shown to be negatively associated with it.

Multiple pregnancies or grand multi gravida are also, according to the findings of this study, associated with a substantially higher risk of dying during the first month after birth. Early identification of multiple pregnancies, referral for appropriate delivery care, and close monitoring during the neonatal period can prevent most of these deaths. ${ }^{2}$

Grandmultipara was not associated with neonatal mortality according to the study findings. The results of this study are in contrast to the data from Kenya Demographic and Health Survey (KDHS) findings which showed that there is generally an increased risk of death for higher-order births. ${ }^{16}$ This could be attributed to risks of complications associated with multi para which include mal presentation, uterine atony, precipitate labour and postpartum hemorrhage (PPH) among others which could lead to poor pregnancy outcome. A population based retrospective cohort study ${ }^{17}$ found that the second births in women aged 15-19 were associated with an increased risk of moderate and extreme prematurity and stillbirths. It has reported ${ }^{18}$ that there were a significant increase in the per inatal mortality, the rate of caesarean section, antenatal maternal

Table 2: Labor and Delivery Factors of Mothers and their association with Neonatal Mortality: Gitwe District Hospital (January, 2013 - July, 2014)

\begin{tabular}{|c|c|c|c|c|}
\hline & Cases n(\%) & Controls n (\%) & Crude OR $(95 \% \mathrm{Cl})$ & Adjusted OR $(95 \% \mathrm{Cl})$ \\
\hline \multicolumn{5}{|l|}{ Place of delivery } \\
\hline Hospital & $30(48.4)$ & $117(62.9)$ & 1 & 1 \\
\hline Health center & $20(32.3)$ & $62(33.3)$ & $1.25(0.66-2.39)$ & - \\
\hline Home & $11(17.7)$ & $4(2.15)$ & $9.8(3.0-32.1)^{* * *}$ & $8.24(2.0-35)^{\star *}$ \\
\hline \multicolumn{5}{|l|}{ Delivery assistance } \\
\hline Doctor & $16(25.8)$ & $86(46.24)$ & 1 & 1 \\
\hline Midwife/nurse & $36(58.06)$ & $92(49.46)$ & $1.40(0.8-2.52)$ & - \\
\hline None & $7(11.3)$ & $5(2.7)$ & $4.60(1.4-15.1)^{\star *}$ & $1.37(0.23-8.21)$ \\
\hline \multicolumn{5}{|l|}{ Mode of delivery } \\
\hline Vaginal & $45(72.6)$ & $109(58.60)$ & 1 & 1 \\
\hline C-section & $13(20.9)$ & $69(37.10)$ & $0.45(0.23-0.9)^{*}$ & $0.52(0.17-1.54)$ \\
\hline \multicolumn{5}{|c|}{ Duration in Labor (hours) } \\
\hline$<12$ & $39(62.90)$ & $133(71.5)$ & 1 & 1 \\
\hline $12-24$ & $7(11.3)$ & $24(12.90)$ & $0.9(0.4-2.5)$ & - \\
\hline $25-48$ & $7(1.3)$ & $2(1.08)$ & $11.9(2.4-59.8)^{\star *}$ & $17.4(2.0-144.2)^{\star *}$ \\
\hline \multicolumn{5}{|c|}{ Delivery complication } \\
\hline None & $50(80.65)$ & $167(89.78)$ & 1 & 1 \\
\hline Hemorrhage & $3(4.84)$ & 15(8.06) & $0.67(0.18-2.40)$ & - \\
\hline Eclampsia & $4(6.45)$ & $1(0.54)$ & $12.7(1.4-16.4)^{*}$ & $23(2.4-25.2)^{\star *}$ \\
\hline
\end{tabular}

Note. OR: odds ratio, CI: confidence intervals ${ }^{\star} \mathrm{p} \leq 0.05,{ }^{* *} \mathrm{p} \leq 0.01,{ }^{* * *} \mathrm{p} \leq 0.001$. 
Table 3: Newborn factors and their association with neonatal mortality: Gitwe District Hospital (January, 2013 - July, 2014)

\begin{tabular}{|c|c|c|c|c|}
\hline & Cases n (\%) & Controls n (\%) & Crude OR $(95 \% \mathrm{Cl})$ & Adjusted OR $(95 \% \mathrm{Cl})$ \\
\hline \multicolumn{5}{|l|}{ Sex of neonate } \\
\hline Female & $16(25.8)$ & $67(36.02)$ & 1 & - \\
\hline Male & $46(74.2)$ & $119(63.98)$ & $1.6(0.8-3.0)$ & \\
\hline \multicolumn{5}{|l|}{ Birth weight(grams) } \\
\hline $\mathrm{NBW}(>=2500)$ & $26(41.94)$ & $144(77.42)$ & 1 & 1 \\
\hline LBW $(<2500)$ & $36(58.06)$ & $42(22.6)$ & $0.21(0.1-0.4)^{\star *}$ & $0.20(0.1-0.5)^{\star *}$ \\
\hline \multicolumn{5}{|c|}{ 1st minute Apgar score } \\
\hline Normal(4-10) & $39(62.8)$ & $195(85.8)$ & 1 & 1 \\
\hline Very lower(0-3) & $11(6.45)$ & $6(3.23)$ & $12.5(4.2-37.7)^{* * *}$ & $7.1(1.6-31.0)^{\star *}$ \\
\hline \multicolumn{5}{|l|}{ Gestational age } \\
\hline Term & $30(48.4)$ & $139(74.73)$ & 1 & 1 \\
\hline Preterm & $29(46.77)$ & $28(15.05)$ & $4.8(2.5-9.2)^{* * *}$ & $3.1(1.3-7.8)^{\star}$ \\
\hline \multicolumn{5}{|l|}{ Birth rank } \\
\hline I & $32(51.61)$ & $65(34.95)$ & $2.1(1.1-3.9)^{*}$ & $3.14(0.2-1.30)$ \\
\hline II-IV & $22(35.48)$ & $94(50.54)$ & 1 & 1 \\
\hline $\mathrm{V}+$ & $8(12.9)$ & $27(14.52)$ & $1.26(0.5-3.1)$ & - \\
\hline \multicolumn{5}{|l|}{ Fetal presentation } \\
\hline Head/vertex & $43(69.35)$ & $160(86.02)$ & 1 & 1 \\
\hline Feet/breech & $8(12.90)$ & $6(3.23)$ & $4.9(1.6-15.0)^{\star *}$ & $1.8(0.4-8.5)$ \\
\hline Transverse & $8(12.90)$ & $6(3.23)$ & $3.7(0.7-19)$ & \\
\hline \multicolumn{5}{|l|}{ Birth spacing } \\
\hline$>=24$ months & $10(16.13)$ & $103(55.38)$ & 1 & 1 \\
\hline$<24$ & $20(32.26)$ & $26(13.98)$ & $0.12(0.05-0.3)^{* * *}$ & $0.1(0.03-0.3)^{* * *}$ \\
\hline \multicolumn{5}{|l|}{ Birth asphyxia } \\
\hline No & $37(59.68)$ & $157(84.4)$ & 1 & 1 \\
\hline Yes & $25(40.32)$ & $29(15.59)$ & $3.6(2.0-7.0)^{\star * \star}$ & $3.2(1.2-8.6)^{*}$ \\
\hline \multicolumn{5}{|l|}{ Neonatal infection } \\
\hline No & $37(59.68)$ & $65(65.05)$ & 1 & - \\
\hline Yes & $25(40.32)$ & $121(34.95)$ & $1.26(0.7-7.0)$ & \\
\hline
\end{tabular}

Note. OR: odds ratio, CI: confidence intervals, LBW: lower birth weight, NBW: normal birth weight

${ }^{*} p \leq 0.05,{ }^{* *} p \leq 0.01,{ }^{* *} p \leq 0.001$.

medical complications and the incidence of PPH among the grand multiparas.

During the course of this study, it has also been found that neonates who were born to the early childbearing ( $<20$ years) mother were more likely to die than those who were born to more than 20 years aged mothers. These findings are in line with those reported ${ }^{19,20}$ previously; even though the findings of the study did not show significant effect of newborn's sex on neonatal mortality. However, the present study findings were not consistent with cross-sectional studies conducted in Swaziland ${ }^{21}$ and in Tanzania, ${ }^{22}$ which found no significant association between maternal age and neonatal mortality.

In this study, it has been also found out that neonates of mothers who have not completion of the antenatal clinic visits were more likely to die than those who completed all 4 visits and got health education repeatedly as predicted by WHO in 2006. Appropriate antenatal care can play a role by educating women and their families to recognize delivery complications that require referral to health care services to achieve a better health outcome for both mothers and infants.

Mothers who had no health insurances were more likely prone to neonatal death than those who had it; this is because women with health insurances are more likely to deliver in a health care facility with a skilled provider.

Moreover, the earlier study stipulated ${ }^{23}$ that, in many Sub Saharan Africa countries, poverty and therefore lack of money for birthpreparedness played an important role on various pregnant outcomes.
In a Prospective study of HIV- infected women, ${ }^{24}$ it has been found out that an aemia, poor weight gain during pregnancy, and low BMI in HIV-infected pregnant women are associated with increased risks of adverse infant outcomes and MTCT of HIV. These results concur with the findings of this study which found out that HIV was associated with neonatal mortality at Gitwe District Hospital. This could be attributed to the fact that HIV/AIDS causes poor maternal health by lowering immunity and especially during pregnancy when immunity is compromised. It could also be as the result of opportunistic infections which may be experienced during pregnancy. Hence, the well-being of the fetus is affected. Another study on pregnancy outcomes in HIV-infected and uninfected women in rural and urban South Africa has found out that HIV-infected women are at a significantly increased risk of adverse pregnancy outcomes and Low-birth-weight infants. ${ }^{25}$

The findings regarding the association between newborn factors and neonatal mortality are also in line with those from other researchers. In the University of Medical Sciences in Iran, it has reported that preterm birth was consistently associated with neonatal mortality. The study conducted in Recife city of Brazil also found out ${ }^{27}$ that prematurity was highly associated with neonatal mortality; the study findings were in line to those from our study where preterm birth newborns are more prone to death than full term babies.

In the current study, sex of neonate was not a risk factor of neonatal mortality, as similar as the study conducted in Kurdistan province of Iran, ${ }^{28}$ but place of delivery (household) which the mentioned previous 
study failed to show significant association with neonatal mortality, is the risk factor of neonatal death according to the findings of this study.

The study findings regarding the association of lower first minute Apgar score, absence of delivery assistant, eclampsia and other delivery complications with neonatal mortality are in line with those disseminated from previous studies. ${ }^{29,30}$ The study in Bangladesh ${ }^{31}$ found out that infants born to women without severe delivery complications had better survival than those born to women with eclampsia, intra-partum hemorrhage, or even prolonged labour.

The limitation of this study was that it only focused on some maternal and newborn factors of neonatal death. Biological and socioeconomic factors of mothers and some clinical factors of newborn such as meconium stained lacked and the validity of the study was affected by that missing information, on both mothers and neonates.

\section{CONCLUSION}

The Study findings pointed out some maternal factors such as labor and delivery factors and some clinical characteristics of neonate at birth that associated with neonatal mortality. From these findings, the researcher would like recommend the social mobilization of the community on reproductive health issues including factors that may lead to low gestation delivery, education on birth preparedness and the importance of attending all four antenatal care visits. Adherence to these factors also helps health care services providers and hospital administrators to reduce neonatal mortality rates and other negative pregnancy outcomes.

\section{ACKNOWLEDGEMENTS}

The author is thankful to the subjects for their heartily cooperation at the time of data collection. He expresses his profound thankfulness to Professor Joseph NTAGANIRA for his constructive instructions, and tireless guidance throughout the course of the study.

\section{CONFLICTS OF INTEREST}

None.

\section{REFERENCES}

1. World Health Organization. Neonatal and perinatal mortality: country, regional and global estimates. [Online].; 2006 [cited 2014 April 30. Available from: http:// whqbdoc.who.int/publications/2006/9241563206.

2. Lawn JE, Cousens, Zupan. Four million neonatal deaths: When? Where? Why? Lancet. 2009; 365(9462):891-900.

3. Peter J, Iliff, Ellen G, Piwoz, Naume V, Tavengwa, et al. Early exclusive breastfeeding reduces the risk of postnatal HIV-1 transmission and increases. AIDS 2005;19(7):699-708.

4. World Health Organization. Road Map for Accelerating The Attainment of Millenium Development Goals Related to Maternal and Newborn Health In Africa. [Online]. London: Partnership Maternal Newborn and Child Health; 2004 [cited 2014 June 14. Available from: http://whqbdoc.who.int/ publications/2004/9241563206.

5. Choi Y, Hill K. Neonatal mortality in the developing world: Demographic research; 2006; 14:429-52.

6. Moss W, Darmstadt GL, Santosham M. Research priorities for the reduction of perinatal and neonatal morbidity in developing country communities. J Perinatol. 2002;22(6):484-95

7. Lawn JE, Kelber C, Enweronu-Laryea, Counsens. 3.6 million neonatal deaths: What is progressin and what is not? Semin Perinatol. 2010;34(7):371-86.
8. Wagstaff A, Lindelow M, Wang S, ZS. Reforming China's rural health system. Wachington, D.C.: The World Bank; 2009.

9. Aimable M, Birgitta E, Cyprien B, Agnes B, Lars-Ake P, Katarina ES. Trends and social differentials in child mortality in Rwanda-2010: results from three demographic and health surveys. Sweden: Uppsala university; 2014. 1990;69(9):834-40.

10. Rebecca W, Thomas P, Anne L, Mivumbi, Ndicunguye V, Hakiba, et al. Trends in Neonatal Mortality In Rwanda, 2000-DHS Further Analysis reports No 88. Calverton, Maryland, USA: Rwanda Demographic and Health Survey(RDHS); 2013. 2010;20(2):311-2.

11. National Institute of Statistics of Rwanda (NISR) [Rwanda], Ministry of Health (MOH) [Rwanda], and ICF. Rwanda Demographic and Health Survey 2014-15: Key Indicators. Kigali:, Rockville, Maryland, USA: NISR, MOH, and ICF International.; 2015.

12. Edmond KM, Zandoh C, Quigley M, Amenga-Etego S, Owusu-Agyei S, Kirkwood BR, et al. Delayed Breastfeeding initiation Increases Risk of Neonatal Mortality. Pediatrics. 2006;117(3):380-6.

13. Rutstein SO. Effects of preceding birth intervals on neonatal, infant and underfive years mortality and nutritional status in developing countries: evidence from the demographic and health surveys. Obstet Gynecol Int J. 2005;89: 7-24.

14. Arokiasamy P, Gautam A. Neonatal Mortality in the Empowered Action Group States of India: Trends and Determinants. J Biosoc Sci. 2008;40(2):183-201.

15. Reid A. Neonatal mortality and stillbirths in early twentieth century Derbyshire, England. Population Studies. 2001;55(3):213-32.

16. Kenya National Bureau of Statistics (KNBS) and ICF Macro. Kenya Demographic and Health Survey 2008-09., Calverton, Maryland: KNBS and ICF Macro; 2010.

17. Smith G, Pell JP, Walsh D. Pregnancy complications and maternal risk of ischaemic heart disease: a retrospective cohort study of 129290 births. Lancet Glob Health. 2001;357(9273): 2002-6.

18. Bondagji NN. The Perinatal and Neonatal Outcome in Grand-Grand Multiparous Women, A Comparative Case Control Study. Bahrain Med Bull. 2005;27(4): 381-9.

19. Faith Y, Jennifer, Williams S, Julie B, Paul N. A retrospective analysis of maternal and neonatal mortality at a teaching and referall hospital in Kenya; 2013.

20. Christiana, Titaley R, Michael, Dibley J, Kingsley, Agho, et al. Determinants of neonatal mortality in Indonesia. 2003;10(13):4755-10.

21. Zwane $E$, Masango S. factors influencing neonatal mortality: Analysis using the Zwaziland Demographic Survey. J Publ Health Af 2012. 2007;2(4):123-31.

22. Ajaa J, Masanja H, Weiner R, Abokyi SA, Owusu-Agyei S. Impact of place delivery on neonatal mortality in rural Tanzania. Int J MCH Aids. 2012;1(1): 4959 .

23. Jelle, Stekelenburg. Health care seeking behaviour and utilisation of health services in Kalabo district Zambia: Kalabo District; 2004.

24. Mehta S, Manji KP, Young AM, Brown ER, Chasela C, Taha ET, et al. Nutritional indicators of adverse pregnancy outcomes and mother-to-child transmission of HIV among HIV-infected women. Am J Clin Nutr. 2008;87(6):1639-49.

25. Rollins CN, Coovadia HM, Bland RM, Coutsoudis A, Bennish ML, Patel D, et al. Pregnancy outcomes in HIV infected and uninfected women in rural and urban South Africa. J HIV AIDS Surveill Epidemiol. 2007:44(3):321-8.

26. Chaman R, Holakouie, Naieni K, Golestan B, Nabavizadeh H. Neonatal mortality risk factors in a rural part of Iran: A nested Case-Control study Iran: University of Medical Sciences; 2008;38(1):48-52.

27. Sarinho S, Filho D, Dasiva G, Lima M. Risk factors for neonatal death in Recife: a case-control study. J Pediatr Mother Care. 2001;77(4):294-8.

28. Esmaeilnasab N, Majdzadeh R. An Epidemiologic study on stillbirth, neonatal mortality and their determinant factors in Kurdistan Province Iran: Hakim; 2002 * 272-7

29. Mostafa, Kamal MS. What is the association between maternal age and neonatal mortality? An analysis of the 2007 Bangladesh Demographic Survey. Asia pac J Public Health. 2011; 20(10):1-12.

30. Conde-Agudelo A, Belizan JM, Lammers C. Maternal-pernatal morbidity and mortality associated with adolescent pregnancy in latin America: Crosssectional study. Am J Obstet Gynecol. 2005;192(2):342-9.

31. Mercer A, Haseen F, Huq NL, Uddin N, Hossain MK. Risk factors for neonatal mortality in rural areas of Bangladesh served by a large NGO programme. Health Policy \& Planning. 2006;21(6):432-43. 